\title{
TEKNOLOGI PENYULINGAN MINYAK SEREH WANGI SKALA KECIL DAN MENENGAH DI JAWA BARAT
}

\author{
Aviasti Anwar ${ }^{1}$, Nugraha $^{2}$, Aswardi Nasution ${ }^{3}$, Reni Amaranti $^{4}$ \\ Jurusan Teknik Industri Fakultas Teknik Universitas Islam Bandung ${ }^{1,2,3,4)}$ \\ Bandung, Jawa Barat, Indonesia \\ E-mail :Aviasti82@mail.com ${ }^{l}$
}

\begin{abstract}
Citronella oil processing industry made a major contribution in improving the economy of the community, especially involve businesses, that is farmers and industrialists. Issues contained in the refining of citronella oil, one of which is requiring relatively large initial costs. The main objective of this research is to create model of industry system for citronella oil processing, small and medium scale so as to optimize the potential and available resources. The first step taken was identify the technologies used, determine the scale of production, how to manage and determine the variables considered to be a critical factor in the refining industry of citronella oil. As of this paper is made, a team of researchers have done several times a survey to see manufactured machine for citronella refining and compare the right technology so citronella oil produced is optimal In addition, researchers conducted a survey to a distillery that uses machine examined, to see firsthand how the refining machine. Stages of research conducted in a structured from preliminary studies, the formulation of the problem and determining the purpose of research, literature studies, define the steps of research, collection of data required, and the design of industrial systems, implementation models, and the final analysis of the results of implementation and improvement models.
\end{abstract}

Keywords : Citronella, Farmers, Refining Technology of Citronella.

\section{PENDAHULUAN}

Indonesia termasuk salah satu produsen utama minyak atsiri dunia dengan kemampuan memasok sekitar $85 \%$ kebutuhan minyak atsiri dunia. Indonesia juga menyimpan potensi yang sangat besar untuk industri minyak atsiri. Pada beberapa tahun terakhir, minyak atsiri mendapat perhatian yang cukup besar dari pemerintah Indonesia melalui berbagai program pada Kementerian Pertanian. Beberapa jenis minyak atsiri yang dihasilkan Indonesia adalah minyak cengkeh, minyak kenanga, minyak nilam, minyak pala, minyak cendana, minyak kayu manis, akar wangi, minyak kayu putih, serta minyak sereh wangi.

Minyak sereh wangi merupakan komoditi di sektor agribisnis yang memiliki pasaran bagus dan berdaya saing kuat di pasaran luar negeri. Sereh wangi sebagai salah satu tanaman yang dapat menghasilkan minyak atsiri juga bisa dijadikan bahan dasar sabun, obat anti nyamuk, pestisida bahkan bahan dasar bio aditif, yang bisa bermanfaat untuk penghemat bahan bakar kendaraan.

Pengembangan tanaman sereh wangi dan pengolahan minyak atsiri memiliki nilai positif yang sangat tinggi karena tidak hanya berkontribusi pada pengembangan pertanian, namun juga turut meningkatkan perekonomian masyarakat. Pengembangan pengolahan minyak sereh wangi di pedesaan merupakan salah satu langkah strategis dalam memacu pertumbuhan perekonomian daerah, selain dapat meningkatkan kesempatan kerja, meningkatkan nilai tambah dan daya saing, serta pendapatan petani tanaman penghasil minyak atsiri.

Oleh karena itu, perlu dirumuskan bagaimana pengembangan industri minyak atsiri di Indonesia termasuk didalamnya pengembangan industri pengolahan minyak sereh wangi harus dilakukan. Selain itu, belum terbukanya industri lanjutan pengolahan minyak sereh wangi serta proses produksi pengolahan minyak sereh wangi yang masih dilakukan secara tradisional dan 
teknologi yang kurang tepat menyebabkan potensi dan sumber daya yang telah ada tidak dapat dikelola secara optimal.

\section{TINJAUAN PUSTAKA}

\subsection{State of The Art}

Penelitian - penelitian mengenai sereh wangi telah banyak dilakukan. Beberapa penelitian membahas mengenai metode penyulingan minyak sereh wangi dan teknologi yang digunakan untuk penyulingan minyak sereh wangi. Penelitian-penelitian tersebut antara lain :

a. Yuni Eko Feriyanto, dkk (2013), mempelajari proses pengambilan minyak atsiri dari daun dan batang sereh wangi menggunakan metode distilasi uap dan air dengan pemanasan microwave dan membandingkan hasil yang diperoleh dengan metode hydro distillation dan steam distillation terdahulu. Penelitian ini juga mempelajari faktor - faktor yang berpengaruh terhadap rendemen dan mutu minyak sereh.

b. Djati Waluyo, dkk (2010), melakukan penelitian studi morfologi dan analisis korelasi antar karakter komponen hasil tanaman sereh wangi dalam upaya perbaikan produksi minyak.

c. Marlon L.P (2012) melakukan penelitian aplikasi perlakuan bahan baku dan penyulingan air - uap terhadap rendemen dan sifat organoleptik minyak atsiri.

Penelitian - penelitian lain mempelajari pemanfaatan minyak sereh wangi untuk berbagai tujuan seperti untuk obat nyamuk dan obat pembasmi hama. Seperti penelitian yang dilakukan oleh Dany Parawita Lubis (2011) yang melakukan uji aktifitas penolak nyamuk dari minyak atsiri daun tumbuhan sereh wangi dalam sediaan lotion. Penelitian lain membahas mengenai identifikasi dan uji toksisitas senyawa sitroneral dari daun sereh wangi sebagai anti feedant terhadap hama thrips pada tanaman jarak pagar (M. Ikbal Fikri, 2010), penelitian mengenai penggunaan ekstrak daun sereh wangi untuk pengendalian jamur penyebab penyakit tepung pada mentimun ( M. Indra Saputra, 2011). Penelitian lain yang menelaah mengenai pemanfaatan sereh wangi adalah penelitian yang dilakukan oleh Haidar (2011) yang melakukan penelitian uji efektifitas sereh wangi sebagai insektisida terhadap nyamuk aedes aigypti dengan metoda fogging. Sedangkan penelitian yang dilakukan oleh Retno Sri Indah Lestari, dkk (2012) membahas mengenai uji finansial terhadap proses isolasi citronellal dan rhodinol pada industri berbasis senyawa turunan minyak sereh wangi. Objek penelitian yang dilakukan Retno dkk adalah industri intermediate dari rantai supply minyak sereh wangi yang akan menghasilkan barang setengah jadi sebagai bahan baku industri hilir.

\subsection{Tentang Tanaman Sereh Wangi}

Sereh wangi adalah tumbuhan dari keluarga rumput-rumputan. Tanaman ini memiliki nama lain Cymbopogon nardus, tumbuh dengan tinggi sekitar $50-100 \mathrm{~cm}$. Berdaun tunggal berjumbai seperti pita dengan panjang sampai 1 meter dan lebar 1,5 $\mathrm{cm}$. Batangnya tidak berkayu, berusukrusuk, dan berwarna putih. Tanaman sereh wangi berkembang biak dengan sistem bonggol akar. Kandungan : Tanaman mengandung zat geraniol, metilheptenon, terpen, terpen-alkohol, asam-asam organik, dan terutama sitronela.

Sebagian besar masyarakat mengenal sereh wangi sebagai bumbu penyedap makanan yang memberi cita rasa dan aroma pada makanan. Hanya sebagian kecil yang mengetahui manfaat sereh wangi sebagai bahan baku untuk citronella oil yang bernilai tinggi dibanding sekedar menjadi bumbu dapur. Citronella oil yang dihasilkan sereh wangi mempunyai bermacam kegunaan diantaranya sebagai bahan baku untuk industri kosmetik, essence, parfum, bahan pewangi, industri farmasi, obat - obatan tradisional, minyak gosok, insektisida, obat anti nyamuk dan lain lain. Tanaman sereh wangi di Indonesia memiliki nama daerah 
yang berbeda - beda, disebut sereh (Jawa, Madura, Sunda, Gayo), sarai (Minang), sorai (Lampung), see (Bali), patahampori (Bima), kedoung witu (Sumba), nou sina (Pulau Roti) dan tenian nalai (Pulau Leti). Tanaman sereh wangi di manca Negara dikenal dengan citronella grass.

\subsection{Metode Penyulingan Minyak Sereh Wangi}

Berikut ini terdapat beberapa metode penyulingan dalam proses produksi minyak sereh wangi. Pada umumnya dalam pengolahan minyak atsiri, dikenal 3 macam metode penyulingan :

\section{1) Penyulingan dengan Air (water distillation)}

Metode penyulingan dengan air merupakan metode paling mudah dibanding metode lainnya. Pada metode ini, bahan tanaman dimasukkan dalam ketel suling yang sudah diisi air sehingga bahan baku daun sereh bercampur dengan air. Metode ini relatif sederhana, demikian juga bahan untuk ketel pun yang mudah didapat. Beberapa penyuling bahkan dapat mengunakan drum bekas oli, minyak tanah, atau drum bekas aspal sebagai ketel. Perbandingan air dan bahan baku daun harus seimbang. Bahan baku dimasukkan dan dipadatkan, selanjutnya ketel ditutup rapat agar tidak ada celah untuk uap keluar. Uap yang hasil perebusan air dan bahan dialirkan melalui pipa menuju ketel kondensator yang mengandung air dingin sehingga terjadi pengembunan (kondensasi). Selanjutnya air dan minyak ditampung dalam tangki pemisah. Pemisahan air dan minyak ini berdasarkan perbedaan berat jenis. Dalam metode penyulingan ini, terdapat kelemahan dimana bila bahan berbentuk tepung dan bunga-bungaan yang mudah membentuk gumpalan jika terkena panas tinggi. Selain itu, karena dicampur menjadi satu, waktu penyulingan menjadi lama dan jumlah minyak yang dihasikan relatif sedikit. Metode penyulingan ini kurang baik dipergunakan untuk bahan fraksi sabun dan bahan yang larut dalam air. Jika tidak diawasi, bahan yang akan disuling dapat hangus karena suhu pemanasan yang tinggi.

2) Penyulingan dengan Air dan Uap (Water And Steam Distillation)

Metode ini disebut juga sistim kukus. Metode pengukusan, bahan diletakkan pada piringan besi berlubang seperti ayakan yang terletak beberapa centi diatas permukaan air. Pada prinsipnya, metode ini menggunakan uap bertekanan rendah, dibandingkan dengan cara water distillation perbedaannya terletak pada pemisahan bahan dan air. Namun penempatan keduanya masih dalam satu ketel. Air dimasukkan kedalam ketel hingga $1 / 3$ bagian. Lalu bahan dimasukkan kedalam ketel sampai padat dan tutup rapat.

Saat direbus dan air mendidih, uap yang terbentuk akan melalui sarangan lewat lubang-lubang kecil dan melewati celahcelah bahan. Minyak atsiri yang terdapat pada bahan ikut bersama uap panas melalui pipa menuju ketel kondensator. Kemudian, uap air dan minyak akan mengembun dan ditampung dalam tangki pemisah. Pemisahan terjadi berdasaran berat jenis. Keuntungan dari metode ini adalah uap yang masuk terjadi secara merata kedalam jaringan bahan dan suhu dapat dipertahankan sampai $100^{\circ} \mathrm{C}$. Metode ini dibandingkan dengan penyulingan air, hasil rendemen minyak lebih besar, mutunya lebih baik dan waktu yang lebih singkat.

3) Penyulingan dengan Uap (Steam

\section{Distillation)}

Sistem penyulingan ini mengunakan tekanan uap yang tinggi. Tekanan uap air yang dihasilkan lebih tinggi daripada tekanan udara luar. Air sebagai sumber uap panas terdapat dalam "boiler" yang terpisah dari ketel penyulingan. Proses penyulingan uap cocok dikakukan untuk bahan tanaman seperti kayu, kulit batang maupun biji bijian yang relatif keras. Pada awalnya metode penyulingan ini dipergunakan tekanan uap yang rendah (kurang lebih 1 atm), kemudian tekanan menjadi 3atm. Jika pada awal penyulingan tekanannya sudah tinggi, maka komponen kimia dalam minyak akan mengalami dekomposisi. Jika minyak dalam bahan diperkirakan sudah habis, maka 
tekanan uap perlu diperbesar lagi dengan tujuan menyuling komponen kimia yang bertitik didih lebih tinggi.

\section{TAHAPAN PENELITIAN}

Penelitian ini merupakan penelitian tahun kedua Penelitian Unggulan Perguruan Tinggi yang dibiayai DIKTI. Pada tahun kedua penelitian ini dilakukan Pada tahap ini dilakukan perancangan tahapan penelitian yang akan dijadikan acuan dalam melakukan penelitian sehingga penelitian dilaksanakan dengan metode penelitian yang runtun dan sistematis sesuai tujuan yang akan dicapai dan waktu penelitian yang telah direncanakan. Pada tahap ini juga dibuat rancangan instrumen pengumpulan data.

\subsection{Pengumpulan Data}

Pengumpulan data dilakukan dengan beberapa cara yaitu wawancara, pengamatan langsung, studi dokumen atau data sekunder, serta uji coba atau melakukan pengujianpengujian untuk mendapatkan data mengenai hasil penyulingan sereh wangi. Secara garis besar, data yang dikumpulkan meliputi :

1) Aliran proses pada industri penyulingan minyak sereh wangi. Aliran proses ini dibutuhkan untuk membuat atau memetakan proses bisnis industri penyulingan sereh wangi. Dengan proses bisnis dapat terlihat bagaimana alur proses bisnis dari awal hingga akhir proses produksi.

2) Teknologi penyulingan sereh wangi. Informasi atau data yang memadai mengenai teknologi yang biasa digunakan untuk penyulingan sereh wangi sangat berguna untuk memodelkan sistem industri penyulingan sereh wangi serta untuk melakukan analsis kelayakan bisnis dari aspek teknis.

3) Data - data penghasil dan pasar sereh wangi. Data penghasil dan pasar sereh wangi yang akan dikumpulkan pada penelitian ini adalah data penghasil dan pasar sereh wangi khusus di wilayah Jawa Barat. Data ini berguna untuk pemetaan rantai pasok terutama untuk memetakan rantai pasok sereh wangi.

\subsection{Pemetaan Rantai Pasok}

Dilakukan untuk mengetahui aliran supply atau pasokan sereh wangi sehingga dapat dianalisis kemungkinan kontinuitas pasokan sereh serta kemungkinan potensi pasar yang akan dimasuki apabila kegiatan industri penyulingan sereh wangi telah dilakukan. Model awal pemetaan rantai pasok sudah diperoleh berdasarkan hasil pengolahan dan analisis data yang dilakukan pada tahun pertama penelitian.

\subsection{Model Sistem Industri Penyulingan Sereh Wangi}

Pada tahap ini dirancang sebuah sistem yaitu sistem industri penyulingan minyak sereh wangi dengan terlebih dahulu mengidentifikasi teknologi yang akan digunakan, menentukan skala produksi yang akan dilakukan, cara mengelola yang akan digunakan dan variabel - variabel lain yang dianggap menjadi faktor kritis dalam sistem industri penyulingan sereh wangi. Perancangan model sistem industri ini menekankan pada optimalisasi potensi dan sumber daya yang dimiliki untuk memperoleh hasil yang maksimal. Hal lain yang menjadi fokus perhatian dalam perancangan sistem ini adalah bahwa sistem industri yang dibuat harus cocok untuk skala kecil dan menengah sehingga dapat menjadi daya tarik masyarakat untuk masuk pada industri ini. Model Sistem industri penyulingan minyak sereh wangi ini merupakan luaran yang ingin diperoleh pada tahun kedua penelitian, sampai makalah ini dibuat Model sistem Industri penyulingan sereh wangi masih dalam proses perancangan.

\section{HASIL DAN PEMBAHASAN}

Pada bagian ini akan diuraikan hasil dari pengumpulan data yang telah dilakukan dengan beberapa cara yaitu wawancara, pengamatan langsung, studi dokumen atau data sekunder, serta uji coba atau melakukan pengujian-pengujian untuk mendapatkan 
data mengenai hasil penyulingan sereh wangi. Pengumpulan data yang dilakukan dimulai dari bulan April sampai dengan bulan Juli 2015, dengan mendatangi beberapa tempat usaha penyulingan minyak sereh wangi yang ada di beberapa Kota di Provinsi Jawa Barat dan Jawa Tengah. Selain itu tim peneliti melakukan survey ke tempat pembuatan mesin penyulingan minyak sereh wangi di Kecamatan Cilongok Purwokerto Jawa Tengah, serta ke tempat penyulingan di Kota Cilacap Jawa Tengah.

\subsection{Teknologi Penyulingan Sereh Wangi}

Informasi atau data yang memadai mengenai teknologi yang biasa digunakan untuk penyulingan sereh wangi sangat berguna untuk memodelkan sistem industri penyulingan sereh wangi serta untuk melakukan analsis kelayakan bisnis dari aspek teknis. Berdasarkan hasil yang diperoleh dari survey lapangan ke beberapa tempat penyulingan minyak sereh wangi di Provinsi Jawa Barat, diperoleh hasil teknologi yang digunakan untuk penyulingan minyak sereh wangi menggunakan dua cara dari tiga cara penyulingan minyak atsiri yaitu :

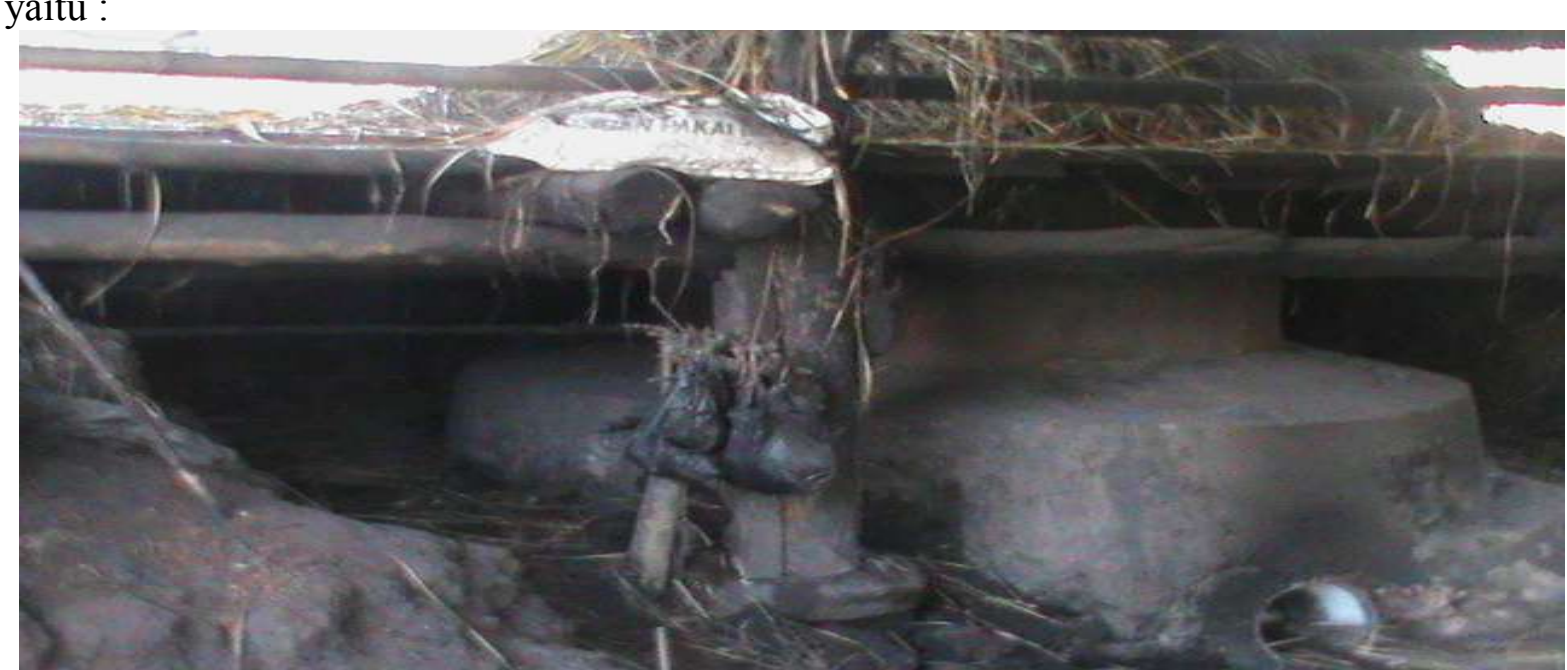

Gambar 1. Penyulingan Minyak Sereh Wangi Di Kampung Palugon Cilacap Jawa Tengah.

2) Penyulingan dengan Air dan Uap (WaterAnd Steam Distillation)

Teknologi ini disebut juga sistim kukus. Cara pengukusan, bahan diletakkan pada piringan besi berlubang seperti ayakan yang terletak beberapa centi diatas permukaan air. Pada prinsipnya, cara ini menggunakan uap
1) Penyulingan dengan Air (Water Distillation)

Teknologi penyulingan dengan air merupakan cara paling mudah dibanding metode lainnya. Pada cara ini, bahan tanaman dimasukkan dalam ketel suling yang sudah diisi air sehingga bahan baku daun sereh bercampur dengan air. Cara ini relatif sederhana, demikian juga bahan untuk ketel pun yang mudah didapat. Beberapa penyuling bahkan dapat mengunakan drum bekas oli, minyak tanah, atau drum bekas aspal sebagai ketel. Perbandingan air dan bahan baku daun harus seimbang. Bahan baku dimasukkan dan dipadatkan, selanjutnya ketel ditutup rapat agar tidak ada celah untuk uap keluar. Uap yang hasil perebusan air dan bahan dialirkan melalui pipa menuju ketel kondensator yang mengandung air dingin sehingga terjadi pengembunan (kondensasi). Selanjutnya air dan minyak ditampung dalam tangki pemisah. Pemisahan air dan minyak ini berdasarkan perbedaan berat jenis. Cara ini dilakukan di Gunung Halu Cililin serta di Kampung Palugon Cilacap Jawa Tengah. 
Saat direbus dan air mendidih, uap yang terbentuk akan melalui sarangan lewat lubang - lubang kecil dan melewati celah celah bahan. Minyak atsiri yang terdapat pada bahan ikut bersama uap panas melalui pipa menuju ketel kondensator. Kemudian, uap air dan minyak akan mengembun dan ditampung dalam tangki pemisah. Pemisahan terjadi berdasaran berat jenis.
Keuntungan dari cara ini adalah uap yang masuk terjadi secara merata kedalam jaringan bahan dan suhu dapat dipertahankan sampai $100^{\circ} \mathrm{C}$. Cara ini dibandingkan dengan penyulingan air, hasil rendemen minyak lebih besar, mutunya lebih baik dan waktu yang lebih singkat, tempat penyulingan yang melakukan cara ini Balitro Lembang, Desa Cimungkal Sumedang dan Desa Ciapus Bogor.
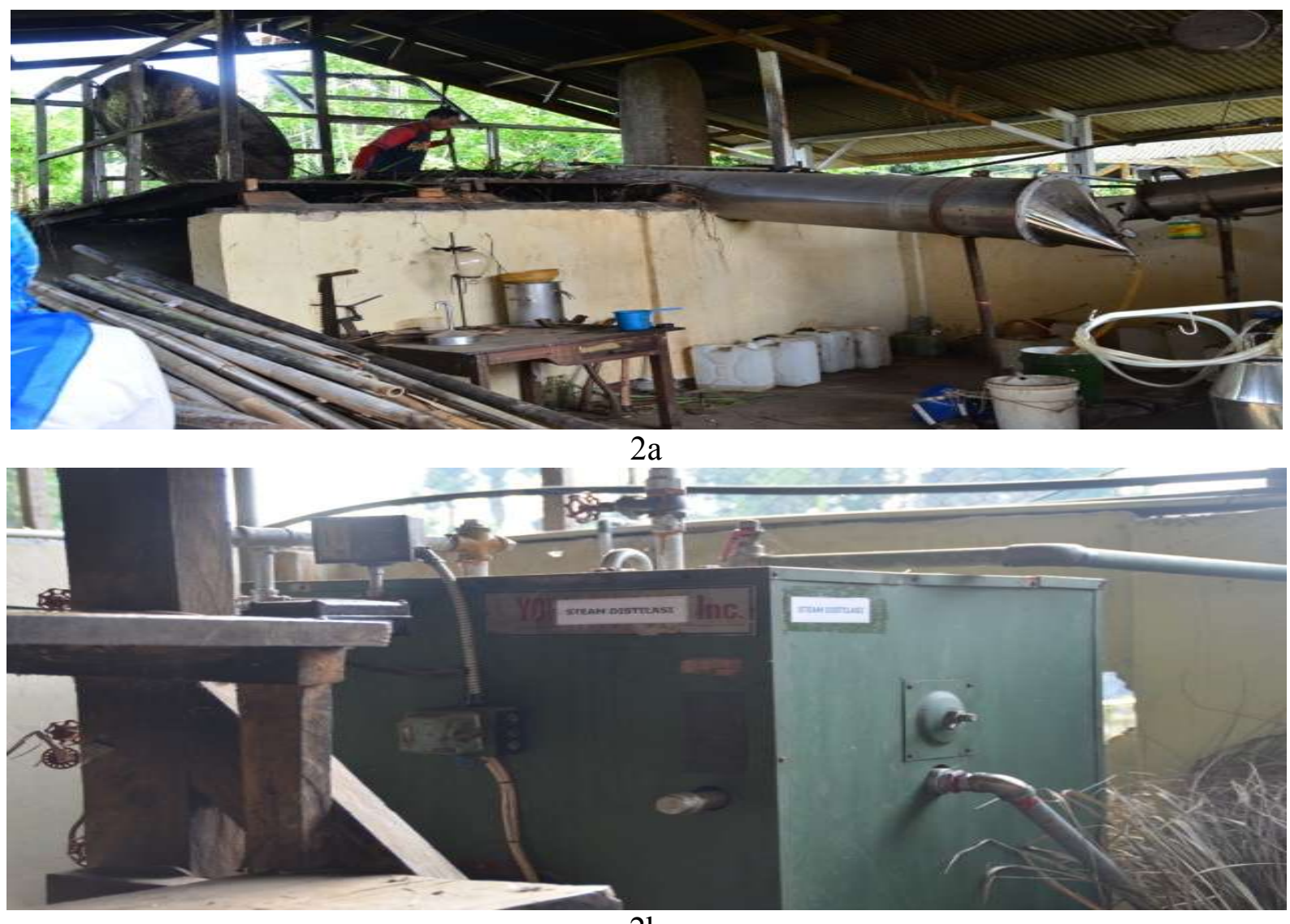

$2 b$

Gambar 2a,b. Penyulingan Minyak Sereh Wangi Di Balitro Manoko Lembang.

\subsection{Hasil Survey ke Kecamatan Cilongok Purwokerto Jawa Tengah}

Menindak lanjuti kunjungan awal untuk penjajagan pada tanggal 8 Oktober 2015 tim peneliti melakukan kunjungan kembali ke pembuat mesin peyulingan minyak serreh wangi di Kecamatan Cilongok Purwokerto Jawa Tengah. Narasumber yang kami kunjungi adalah Bapak Muhdori yang meneruskan jejak orang tuanya sebagai pembuat mesin penyulingan minyak sereh wangi dan minyak atsiri lainnya. Bapak Mudhori belajar proses pembuatan mesin tersebut sejak kelas 5 SD dan selalu mempelajari kekurangan-kekurangan dari mesin yang dibuat secara otodidak sehingga diperoleh mesin penyulingan yang dapat menghasilkan rendeman dan kualitas minyak sereh wangi yang tinggi.

Berdasarkan pengalaman - pengalaman yang diperoleh maka yang bersangkutan dapat membuat mesin penyulingan yang memenuhi syarat yaitu menghasilkan kualitas rendeman dan minyak sereh wangi yang tinggi. Faktor yang mempengaruhi terhadap kualitas minyak sereh wangi adalah 
bahan baku mesin yang digunakan serta bentuk dari mesin yang dibuat. Mesin penyulingan minyak sereh wangi yang dibuat Bapak Mudhori satu setnya terdiri dari tiga unit, dimana masing-masing unit mempunyai fungsi yang berbeda. Lokasi penyulingan yang sudah menggunakan mesin buatan Bapak Mudhori di Desa Cimungkal, kualitas rendeman dan 40 minyak sereh wangi yang dihasilkan terbukti meningkat semula menggunsakan mesin lama 30\% setelah menggunakan mesin baru menjadi $40 \%$ dengan proses penyulingan selama 3 jam.

Pada penelitian tahap kedua ini tim peneliti mengunjungi kembali bengkel pembuatan mesin penyulingan minyak sereh wangi di Kecamatan Cilongok untuk melihat secara detail proses pembuatan mesin penyulingan tersebut. Berdasarkan hasil wawancara diperoleh beberapa informasi sebagai berikut :

Proses pembuatan mesin penyulingan yang dilakukan di bengkel Las Harapan Mulya ada dua cara yaitu dengan cara :

a. Sistem broiler dengan kapasitas $800 \mathrm{~kg}$ sampai dengan 1 ton sereh wangi, sistem ini dapat menghasilkan minyak sereh wangi yang bagus karena proses pengapiannya stabil dan sudah di stell dengan menggunakan 3 buah dandang. Proses pembuatan mesin penyulingan dengan sistem broiler untuk 1 set menghabiskan waktu selama 1 bulan. Penutup untuk proses penyulingannya harus pas dan tidak boleh terlalu rapat, karena akan berpengaruh pada proses penyulingannya. Khusus sereh wangi dan nilam proses penyulinganya harus baik agar kualitas trendeman yang dihasilkan bagus karena berpengaruh ke harga jual, sedangkan untuk bahan baku minyak atsiri yang lain tidak dipengaruhi oleh kualitas rendeman karena tetap laku terjual.

Spesifikasi dan Ukuran Alat Penyulingan dengan sistem broiler sebagai berikut :
- Alat penyulingan terdiri dari boiler (ketel pendidih air), ketel penyulingan (destillation), ketel pendingin dan penampungan minyak sereh wangi.

- Boiler; berfungsi untuk mendidihkan air, kemudian uapnya dialirkan dengan pipa sepanjang dua meter ke ketel penyulingan. Dengan cara ini temperatur uap relatip stabil yang diperlukan untuk mengukus daun sereh wangi di dalam ketel penyulingan.Boiler terbuat dari pelat dengan tebal $4 \mathrm{~mm}$ atau $5 \mathrm{~mm}$ dan ukuran boiler yaitu diameter $1,5 \mathrm{~m}$ dan tinggi 1,2 m.

- Ketel Penyulingan; ukuran ketel penyulingan, diameter $1,5 \mathrm{~m}$ dan tinggi $1,8 \mathrm{~m}$ terbuat dari pelat tebal $4 \mathrm{~mm}$ atau $5 \mathrm{~mm}$. Kapasitas ketel dengan ukuran ini dapat memuat daun sereh wangi sebanyak satu ton. Uap sereh wangi hasil pengukusan dialirkan dengan pipa sepanjang 1,5 $\mathrm{m}$ ke ketel pendingin.

- Ketel Pendingin; terbuat dari pelat yang sama dengan boiler dan ketel penyulingan dengan ukuran diameter 1,8 $\mathrm{m}$ dan tinggi $2,4 \mathrm{~m}$ diisi dengan pipa spiral dan air.

- Penampungan Minyak Sereh Wangi; minyak sereh wangi yang masih bercampur dengan air dari ketel pendingin, ditampung dengan ember plastik 20 liter. Di dalam ember penampungan, minyak sereh wangi akan terpisah dengan air. Minyak sereh wangi berada di atas air karena berat jenis air lebih besar dari minyak, kemudian diambil dengan gayung dan dimasukkan ke dalam jerigen atau kompan.

Pemasangan Alat Penyulingan dengan sistem broler sebagai berikut :

- Boiler diletakkan lebih rendah dari ketel penyulingan, bagian atas boiler rata dengan bagian dasar ketel penyulingan. Bagian atas boiler dengan bagian bawah ketel penyulingan (lebih kurang $20 \mathrm{~cm}$ dari dasar) dihubungkan dengan pipa diameter 2 inchi sepanjang $2 \mathrm{~m}$. 
- Bagian dasar boiler dengan dasar tempat kayu bakar atau bisa juga bahan bakar dari sisa penyulingan berjarak kurang lebih $40 \mathrm{~cm}$, jarak ideal yang diperoleh dari pengalaman para pelaku penyulingan. Sekeliling boiler ditembok dengan jarak bagian depan $20 \mathrm{~cm}$ dan bagian belakang $15 \mathrm{~cm}$. Kemudian dibuat lorong pembuangan asap yang dihubungkan dengan cerobong asap.

- Bagian atas ketel penyulingan dan pipa spiral di ketel pendingin dihubungkan dengan pipa sepanjang 1,5 m. Bagian atas ketel penyulingan dengan bagian atas ketel pendingin sama rata. Ember penampungan minyak sereh wangi diletakkan dekat dengan bagian bawah ketel pendingin. Bagian atas ember sama rata dengan dasar ketel pendingin dan dihubungkan dengan pipa diameter 2 inchi dengan panjang sesuai keperluan.

- Berdasarkan pengalaman para pelaku penyulingan, ketel penyulingan kapasitas $500 \mathrm{~kg}$ daun sereh wangi memerlukan dua orang tenaga kerja, begitu juga ketel kapasitas $1000 \mathrm{~kg}$. Bahan bakar yang digunakan juga relatif sama untuk kedua kapasitas tersebut. Oleh karena itu, pelaku penyulingan lebih menyukai kapasitas $1000 \mathrm{~kg}$ atau satu ton.

b. Sistem kukus yang menggunakan langseng dengan diameter 150 dan 180 $\mathrm{cm}$, tetapi hasilnya tidak begitu bagus karena harus selalu mengatur dan menyesuaikan proses pengapiannya. Sistem kukus kapasitasnya sekitar 80 $100 \mathrm{~kg}$. Proses pembuatan mesin penyulingan dengan sistem kukus menghabiskan waktu 10 hari. Untuk sistem langseng hanya memerlukan satu dandang dan pipanya dapat langsung dialirkan ke kolam. Tetapi jika pipanya tidak dialirkan ke kolam, maka harus ada dua buah dandang dimana yang satunya untuk tempat pipa. Agar proses pengapiannya bagus maka dibuat juga tungku dari lima buah batu sarangan, batu sarangan ini dalam kondisi panas tidak dapat disiram dengan air karena akan menyebabkan patah. Lima buah batu tersebut diletakkan dibawah dandang yang berdiameter $160 \mathrm{~cm}$ dengan jarak masing-masing batu sekitar $30 \mathrm{~cm}$.

\section{KESIMPULAN}

a. Permintaan minyak sereh wangi ke Indonesia setiap tahunnya lebih dari dua ribu ton, dan baru dapat memenuhi sekitar 8\%. Negara - negara yang menjadi pasar minyak sereh wangi di dunia antara lain negara - negara Timur Tengah dan Cina.

b. Rantai perdagangan domestik minhyak atsiri yang juga mencerminkan minyak sereh wangi memperlihatkan urut-urutan sebagai berikut: petani - pengepul industri kecil penyulingan dan industri pengolah (eksportir).

c. Teknologi yang digunakan untuk penyulingan minyak sereh wangi menggunakan dua cara dari tiga cara penyulingan minyak atsiri yaitu penyulingan dengan air (water distillation) dan penyulingan dengan air dan uap (water and steam distillation).

d. Di perlukan tata letak pengelolaan yang baik tentang masalah proses penyulingan dari mulai kedatangan bahan baku daun minyak kayu putih, cara memasukan kedalam ketel, proses pemadatan daun kayu putih yang akan dikukus, pemakaian alat K3, penyimpanan / gudang sisa proses pengukusan sehingga tidak mudah terjadi kebakaran, proses pembakaran yang harus diperhatikan, luas lahan yang ideal untuk tempat pentulingan, adanya tempat istirahat untuk pegawai, proses pengelolaan air untuk mendinginkan proses penyulingan.

\section{Ucapan Terima Kasih}

Ucapan terima kasih kami sampaikan kepada Dirjen Pendidikan Tinggi yang telah membiayai Penelitian Unggulan Perguruan Tinggi ini yang pada saat ini masuk tahun kedua melalui proses seleksi proposal usulan penelitian yang diajukan pada tahun 2014 . 


\section{DAFTAR PUSTAKA}

Danny Parawita Lubis, 2011. Uji Aktivitas Penolak Nyamuk Dari Minyak Atsiri Daun Tumbuhan Sereh Wangi (Cymbopogon nardus (L.) Rendle) Dalam Sedian Lotion, Skripsi, Fakultas Farmasi Universitas Sumatera Utara.

Djati Waluyo Djoar, Panut Sahari, dan Sugiyono, Studi Morfologi dan Analisis Korelasi Antar Karakter Komponen hasil Tanaman Sereh Wangi (Cymbopogon sp.), Skripsi, Fakultas Pertanian UNS, Surakarta.

Egi Aguatian, Anny Sulaswaty, Tasrif, Joddy Arya L., dan Indri Badria, Pemisahan Citronellal dari Minyak Sereh Wangi Menggunakan Unit Fraksionasi Skala Bench, Jurnal Tek. Industri Pertanan, Vol. 17(2), hal 45-53.

Inaas Azmi Haidar, 2011. Uji Efektivitas Ekstrak Serai Wangi (Cymbopogon nardus) Sebagai Insektisida Terhadap Nyamuk Aedes Aegypti Dengan Metode Fogging, Tugas Akhir, Fakultas Kedokteran Universitas Brawijaya.

Owi Setyaningsih. Erliza Hambali, dan Muharamia Nasution, Aplikasi Minyak Sereh Wangi (Citronella Oil) dan Geraniol Dalam Pembuatan Skin Lotion Penolak Nyamuk, Jurnal Teknologi Industri Pertanian, Volume 17 (3), hal. 97-103.

Retno Sri Indah L., Djumali M., Ani S., Anas Miftah, dan Meika Syahbana R., 2012. Kajian Finansial Isolasi Citronellal dan Rhodinol Pada Industri Berbasis Senyawa Turunan Minyak Sereh Wangi, Agrointek Volume 6 Nomor 1, hal. 45-54.
Rohimatun dan I Wayan Laba, 2013. Efektifitas Insektisida Minyak Sereh Wangi dan Cengkeh Terhadap Hama Pengisap Buah Lada (Dasynus Piperis China), Buletin Littro, Volume 24 Nomor 1.

Sentosa Ginting, 2004. Pengaruh Lama Penyulingan Terhadap Rendemen Dan Mutu Minyak Atsiri Daun Sereh Wangi, e-USU Repository.

Supriyanto, 2008. Potensi Ekstrak Sereh Wangi (Cymbopogon Nerdus L) Sebagai Anti Streptoccus Mutans, Skripsi, Program Studi Biokimia Fakultas MIPA IPB.

Yuni Eko F, Patar Jonathan S., Mahfud, dan Pantjawarni P, 2013. Pengambilan Minyak Atsiri dari Daun dan Batang Serai Wangi (Cymbopogon Winterianus) Menggunakan Distilasi Uap dan Air dengan Pemanasan Microwave, Jurnal Teknik POMITS, Vol 2 No 1, ISSN 2337-3539 (2301-9271 Print). 